\title{
IDENTIFIKASI UNSUR BORON MENGGUNAKAN TEKNIK LASER INDUCED BREAKDOWN SPECTROSCOPY (LIBS) UNTUK MENDETEKSI KANDUNGAN BORAKS PADA MAKANAN
}

\author{
Chandra Wijaya $^{1, a)}$, Mangasi Alion Marpaung ${ }^{1, b)}$, Indra Karnadi ${ }^{2, a)}$ \\ ${ }^{1}$ Program Studi Fisika Universitas Negeri Jakarta, Indonesia. \\ ${ }^{2}$ Maju Makmur Mandiri Research Center, Indonesia. \\ Email: ${ }^{\text {a) }}$ chandraw8999@gmail.com, ${ }^{\text {b) }}$ mangasi@unj.ac.id (corresponding author)
}

\begin{abstract}
Abstrak
Dalam penelitian ini dikembangkan suatu metode untuk mendeteksi kandungan boraks dalam makanan dengan menggunakan teknik Laser Induced Breakdown Spectroscopy (LIBS). Dalam teknik ini boraks (Na2B4O7) yang berupa serbuk dicampur dengan bahan makanan (tepung) dengan konsentrasi boron sebanyak 1\%, 3\%, 5\%, 7\%, dan 10\% dalam 10 gram sampel. Sampel yang sudah digerus sampai halus kemudian dikompaksi untuk menjadi pellet dengan diameter $10 \mathrm{~mm}$ dan tebalnya antara 1-2 mm. Dalam penelitian ini digunakan berkas laser dari Nd:YAG (355 nm, $8 \mathrm{~ns})$ yang difokuskan pada permukaan sampel pellet sehingga timbul plasma. Spektrum emisi plasma yang terekam pada komputer kemudian dianalisis untuk melihat garis emisi boron yang menandakan kehadiran boraks pada sampel.
\end{abstract}

Kata-kata kunci: Laser Induced Breakdown Spectroscopy (LIBS), spektrum emisi plasma, boron.

\begin{abstract}
In this study a method was developed to detect borax content in food using the Laser Induced Breakdown Spectroscopy (LIBS) technique. In this technique borax (Na2B4O7) in the form of powder is mixed with food ingredients (flour) with a boron concentration of $1 \%, 3 \%, 5 \%, 7 \%$, and $10 \%$ in a 10 gram sample. Samples that have been crushed until smooth are then compacted to become pellets with a diameter of $10 \mathrm{~mm}$ and thickness between 1-2 mm. In this study a laser beam from Nd: YAG (355 $\mathrm{nm}$, $8 \mathrm{~ns}$ ) was focused on the surface of the pellet sample so that plasma arises. The plasma emission spectrum recorded on the computer is then analyzed to see the boron emission line that indicates the presence of borax in the sample.
\end{abstract}

Keywords: Laser Induced Breakdown Spectroscopy (LIBS), spectrum of plasma emission, boron.

\section{PENDAHULUAN}

Indonesia adalah negara yang kaya akan tradisi, budaya dan kulinernya. Setiap daerah di Indonesia memiliki makanan khas masing-masing. Selain kaya akan makanan khas daerah, Indonesia juga kaya akan makanan olahan. Makanan olahan adalah makanan yang diproduksi dengan mengubah bentuk dan rasa dari bahan asli untuk alasan kepraktisan dan keawetan.

Makanan olahan sangat mudah ditemui, baik di toko-toko sekitar maupun penjual yang berkeliling. Beberapa contoh makanan olahan adalah bakso, mie, sosis, dan nugget. Banyaknya penjual makanan olahan mengakibatkan persaingan diantara para penjual yang meningkatkan risiko 
penggunaan zat tambahan makanan berbahaya untuk mengawetkan makanan olahan. Menurut laporan BPOM di Jakarta 2018, boraks adalah zat tambahan makanan dengan persentasi tertinggi yang digunakan sebagai bahan pengawet pada makanan [6].

Penggunaan boraks sebagai zat tambahan dalam makanan telah dialarang di Indonesia [8]. Apabila terkonsumsi manusia, boraks dengan dosis tinggi dapat bersifat racun. Namun masih banyak penjual yang mencampurkan boraks sebagai pengawet makanan dan membuat tekstur makanan lebih kenyal. Sulit untuk membedakan makanan yang mengandung boraks dengan yang tidak jika hanya menggunakan panca indera. Berdasarkan hal tersebut maka diperlukan metode untuk mengetahui apakah suatu produk makanan terkontaminasi boraks.

Metode terbaru untuk melihat kandungan suatu material adalah dengan menganalisis unsur-unsur yang terkandung pada material tersebut. Analisis spektrokimia merupakan metode analisis yang paling sering digunakan untuk mengidentifikasi unsur-unsur yang terkandung pada suatu material baik secara kuantitatif maupun kualitatif berdasarkan spektrum yang dihasilkan. Dalam menganalisis unsur pada suatu material dilakukan dengan menggunakan metode Atomic Absorption Spectroscopy atau Atomic Emission Spectroscopy [12].

Metode Atomic Absorption Spectroscopy (AAS) adalah salah satu metode untuk menganalisis unsur terutama unsur logam dan metaloid dengan konsentrasi rendah. Atomic Absorbtion Spectroscopi (AAS) adalah spektroskopi yang berprinsip pada serapan cahaya oleh atom. Atom-atom menyerap cahaya pada panjang gelombang tertentu, tergantung pada unsurnya. Pada metode ini sampel harus diubah kedalam fase cair. Sampel yang dilarutkan hanya dapat digunakan untuk larutan dengan konsentrasi rendah dan memerlukan jumlah larutan yang relatif besar (10-15 ml). Persiapan sampel yang sulit menjadikan metode ini memiliki kekurangan dalam segi preparasi sampel.

Salah satu metode analisis unsur yang sedang berkembang pesat adalah metode Laser Induced Breakdown Spectroscopy (LIBS). Teknik Laser Induced Breakdown Spectroscopy (LIBS) merupakan salah satu pengembangan dari metode Atomic Emission Spectroscopy. Teknik LIBS memiliki beberapa keunggulan dibandingkan dengan teknik analisis lainnya antara lain preparasi sampel yang digunakan cukup sederhana, pendeteksian dapat dilakukan dengan cepat (rata-rata 5 detik), dapat melakukan analisa secara real-time dengan tingkat akurasi ber-orde part per million (ppm), serta dapat mengukur hampir semua unsur kimia termasuk elemen yang ringan, seperti $\mathrm{H}, \mathrm{Be}, \mathrm{Li}, \mathrm{C}, \mathrm{N}, \mathrm{O}$, $\mathrm{Na}$, dan Mg secara serempak [4].

Prinsip dasar Teknik LIBS yaitu memfokuskan laser daya tinggi pada permukaan sampel dalam tekanan atmosfer atau tekanan rendah sehingga membangkitkan plasma. Pada plasma elektron pada tingkat energi dasar akan terkesitasi ke tingkat energi yang lebih tinggi. Kemudian elektron yang tereksitasi akan kembali ke tingkat energi dasar (ground state) dengan melepaskan/mengemissikan kelebihan energi berupa cahaya (foton) dengan spektrum yang mempunyai karekteristik berbeda pada setiap unsur. Emisi plasma tersebut akan ditangkap oleh spektrometer yang disalurkan melalui serat optik dan spektrumnya akan ditampilkan pada personal computer. Intensitas spektrum menyatakan konsentrasi atau jumlah suatu unsur yang berada dalam sampel, sedangkan panjang gelombang menunjukkan jenis unsur pada suatu sampel [13].

Beberapa analisis kandungan unsur suatu material dengan menggunakan teknik LIBS sudah pernah dilakukan sebelumnya. Salah satunya adalah identifikasi kandungan unsur-unsur pada tiga varietas serbuk kopi [10]. Penelitian sebelumnya menunjukkan bahwa teknik LIBS dapat menganalisis kandungan unsur-unsur suatu material secara akurat tanpa perlu perawatan sampel rumit dan langkah-langkah pemurnian. Pada penelitian ini akan dilakukan identifikasi kontaminan boraks dengan indikator unsur boron (B) menggunakan teknik LIBS, spektrum panjang gelombang yang dihasilkan dari unsur boron (B) berdasarkan National Institute of Standards and Technology (NIST) LIBS Database, yaitu $249 \mathrm{~nm}$.

\section{METODE PENELITIAN}

Pada penelitian ini perangkat yang digunakan laser pulsa Nd:YAG (third harmonic Quanta Ray, LAB SERIES, $355 \mathrm{~nm}, 100 \mathrm{~mJ}, 8 \mathrm{~ns}$ ) yang dioperasikan pada mode $Q$-Switch pada frekuensi repetisi $10 \mathrm{~Hz}$ sebagai sumber irradiasi dan difokuskan dengan lensa pemfokus $(\mathrm{f}=120 \mathrm{~mm})$ melalui jendela quartz ke permukaan sampel yang ditempatkan pada suatu chamber. Emisi plasma dikirim ke suatu 
spektrometer melalui fiber optik yang ditempatkan sedemikian sehinnga dapat menangkap seluruh emisi plasma.

Sampel makanan yang digunakan pada penelitian ini adalah bahan dasar yang biasa digunakan pada berbagai makanan olahan yaitu tepung terigu yang dicampurkan dengan Boraks dengan konsentrasi boron (B) sebanyak 1\%, 3\%, 5\%, 7\%, dan 10\% dalam 10 gram sampel. Sampel yang berbentuk serbuk digerus sampai halus kemudian diberi perlakuan awal dengan dikompaksi untuk menjadi pellet dengan diameter $10 \mathrm{~mm}$ dan tebalnya antara 1-2 $\mathrm{mm}$ agar sampel serbuk menjadi padat.

Sampel ditempatkan pada ruang yang terbuat dari logam berukuran $(11 \mathrm{x} 11 \mathrm{x} 12,5 \mathrm{~cm} 3)$, yang dapat divakumkan dengan pompa vakum dan dapat diisi gas/udara sesuai dengan tekanan yang diinginkan. Aliran gas/udara ddialirkan melalui suatu needle valve dan tekanan dalam ruang vakum dimonitor dan diukur dengan digital pirani meter. Pada penelitian ini diatur tekanan didalam ruang sampel sebesar 5 torr dan energi laser sebesar $20 \mathrm{~mJ}$. Skema peralatan teknik LIBS yang digunakan dalam penelitian ini ditampilkan dalam GAMBAR 1.

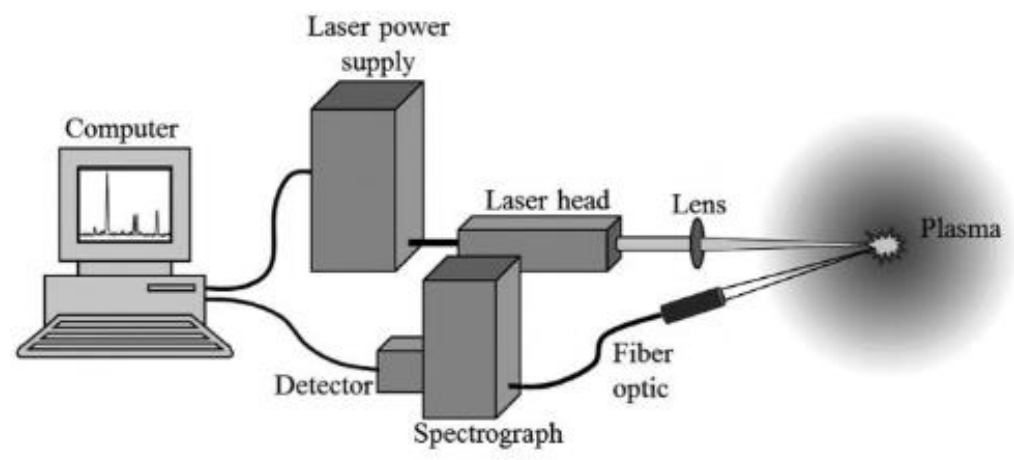

GAMBAR 1. Skema peralatan teknik LIBS.

Laser Nd:YAG diiradiasi kearah sampel yang telah dibentuk pellet dengan tekanan gas dan energi laser yang sudah ditentukan. Iradiasi laser difokuskan pada sampel, sehingga interaksi laser dengan material akan mengevaporasi sebagian kecil dari sampel. Evaporasi (penguapan) ini merupakan perubahan fase dari material padat menjadi gas dengan temperatur tinggi, gas inilah yang merupakan plasma.

Emisi plasma yang dibangkitkan dari sampel kemudian dideteksi oleh fiber optik dan ditransmisikan ke spektrometer yang telah dihubungkan dengan komputer. Data spektrum emisi disimpan dengan format ASCII yang selanjutnya diolah dengan program SciDAVis untuk dibuat grafik hubungan antara panjang gelombang dan intensitas. Spektrum emisi yang didapatkan diidentifikasi menggunakan basis data spektrum atom dari NIST LIBS Database yang dapat diakses secara online tanpa berbayar.

\section{HASIL DAN PEMBAHASAN}

Pada penelitian ini, spektrum emisi diamati dari plasma yang dibangkitkan pada sampel campuran tepung terigu dan boraks dengan konsentrasi boron sebanyak 1\%, 3\%, 5\%, 7\%, dan $10 \%$ yang dibuat dalam bentuk pellet dengan energi laser sebesar $20 \mathrm{~mJ}$ dan dalam lingkungan udara pada tekanan sebesar 5 torr. GAMBAR 2 memperlihatkan spektrum emisi pada daerah panjang gelombang 235$260 \mathrm{~nm}$. 


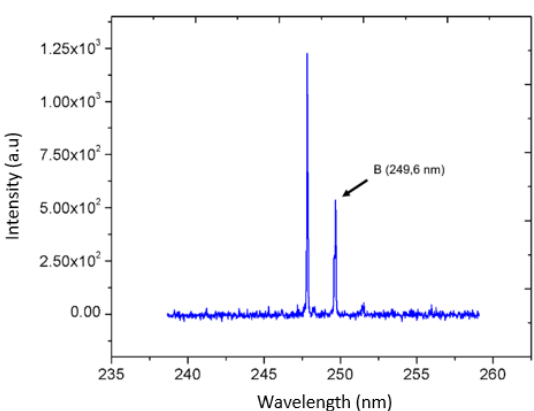

a.

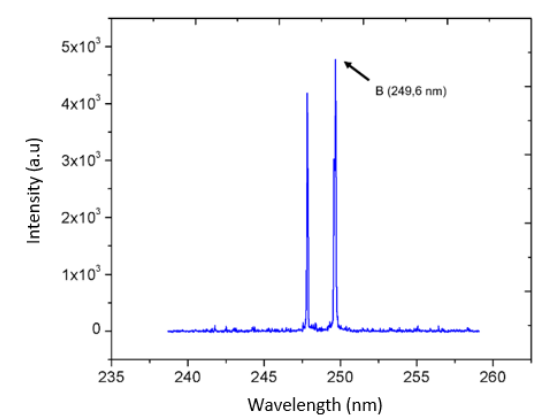

C.

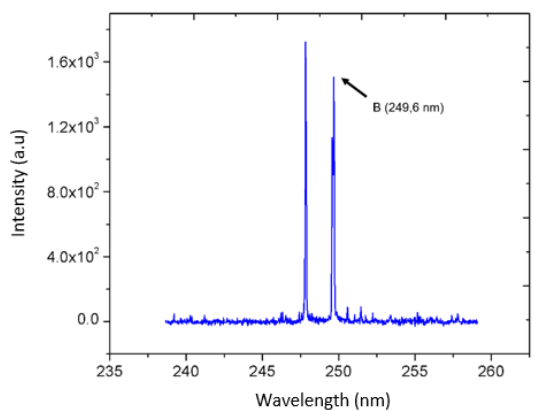

b.

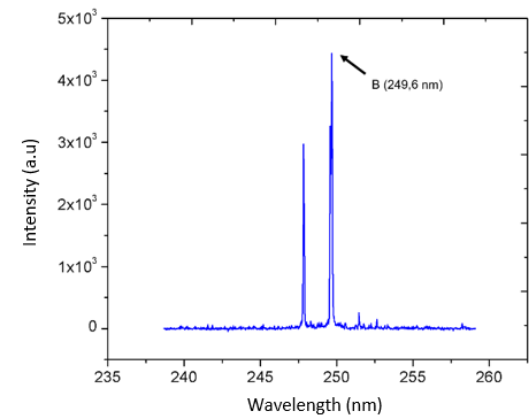

d.

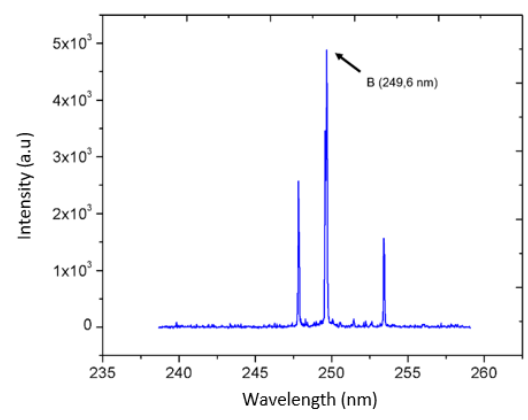

e.

GAMBAR 2. Spektrum emisi kontaminan Boron a.) $1 \%$, b.) $3 \%$, c.) $5 \%$, d.) $7 \%$, e.) $10 \%$, pada keadaan tekanan udara 5 torr dan energi laser $20 \mathrm{~mJ}$.

Pada GAMBAR 2 tersebut dapat dilihat dengan jelas spektrum emisi spektral dari unsur boron (B) pada panjang gelombang 249,68 nm. Faktor-faktor yang mempengaruhi terlihatnya spektrum emisi antara lain sampel yang sudah dikompaksi berbentuk padat sehingga ketika sampel diirradiasi dengan laser maka sampel tidak hancur yang membuat laser dapat fokus ditembakkan pada sampel di satu titik. Penggunaan tekanan gas rendah (5 torr) juga berpengaruh terhadap spektrum emisi. Jika kerapatan gas penyangga semakin kecil maka plasma yang mengembang dengan mudah menekan gas sekitarnya sehingga plasma merambat dengan cepat dan ketika tereksitasi akan terlihat emisinya dengan jelas.

Energi laser yang diberikan juga berpengaruh terhadap spektrum emisi. Pada prinsipnya laser memiliki ambang batas energi yang dipompakan. Jika energi yang berikan terlalu besar maka sampel akan lebih cepat rusak dan akan memperpendek usia penggunaan laser. Sebaliknya, jika energi yang diberikan terlalu kecil maka emisi yang dihasilkan tidak akan cukup atau kurang bagus. Spektrum emisi yang terlihat jelas menunjukkan bahwa energi laser yang digunakan, yaitu $20 \mathrm{~mJ}$ termasuk kedalam energi optimal yang dapat digunakan pada sampel ini.

Spektrum emisi kelima sampel menunjukkan bahwa dengan meningkatnya konsentrasi boron (B) maka intenstitas spektrum emisi yang dihasilkan juga meningkat, dengan konsentrasi boron (B) $10 \%$ memiliki intensitas spektrum yang paling tinggi dibandingkan dengan sampel lainnya, meskipun 
pada sampel dengan konsentrasi boron (B) 5\% memiliki intensitas lebih tinggi daripada intensitas sampel dengan konsentrasi boron (B) 7\%. Dari spektrum emisi yang didapatkan belum bisa diperoleh linieritas antara intensitas spektrum emisi terhadap sampel, akan tetapi dari spektrum emisi sampel bisa diketahui batas deteksi boron (B) menggunakan metode ini. Berdasarkan perhitungan diperoleh batas deteksi boron (B) sebesar 0,61 mg/g sampel.

\section{KESIMPULAN}

Hasil penelitian menunjukkan bahwa metode ini dapat digunakan untuk mengidentifikasi unsur boron (B) pada sampel campuran tepung terigu dan boraks, dan memberikan hasil analisa yang cepat dan real time. Pada kelima sampel dapat dilihat dengan jelas spektrum emisi spektral dari unsur boron (B) pada panjang gelombang 249,68 nm. Dengan meningkatnya konsentrasi boron (B) maka didapatkan peningkatan intenstitas spektrum emisi yang dihasilkan, meskipun belum dapat diperoleh peningkatan yang bersifat linier, akan tetapi dapat diperoleh batas deteksi boron (B) sebesar 0,61 $\mathrm{mg} / \mathrm{g}$ sampel.

\section{UCAPAN TERIMAKASIH}

Ucapan terimakasih ditujukan kepada semua pihak yang telah membantu dalam penelitian ini yaitu:

1. Dr. Koo Hendrik Kurniawan sebagai direktur / owner Maju Makmur Mandiri Research Center dimana penelitian ini dilakukan,

2. Dr. Marincan Pardede selaku staf peneliti pada Makmur Mandiri Research Center / Universitas Pelita Harapan atas bantuannya dalam pengambilan data.

\section{REFERENSI}

[1] J. Cremers, A. David \& L. J. Radziemski, "Handbook of Laser-Induced Breakdown Spectroscopy," John Wiley \& Sons, 2013.

[2] Declarossy, et al., "Analisis Unsur Ag Pada Sampel Cair Dengan Laser Induced Breakdown Spectroscopy (LIBS)," Buletin Fisika, vol. 15, no. 1, pp. 16-23, 2014.

[3] Halim, et al., "Boron Removal from Aqueous Solution Using Curcumin-impregnated Activated Carbon," Sains Malaysiana, pp. 1293-1300, 2013.

[4] Idris, et al., "Karakteristik Fisik Plasma dalam Laser-Induced Breakdown Spectroscopy (LIBS) Menggunakan Laser Neodymium:Yttrium-Aluminum-Garnet (Nd-YAG) Pada Sampel Daging Kerang Sungai," Risalah Fisika, vol. 2, no. 1, pp. 9-14, 2018.

[5] I. Khasanah, "Analisis Kandungan Unsur pada Emisi Gas Buang Kendaraan Bermotor Bahan Bakar Bensin Premium, Pertalite, dan Pertamax Menggunakan Teknik Laser Induced Breakdown Spectroscopy (LIBS)," Prosiding Seminar Nasional Fisika (E-Journal) SNF2019, pp. 153-160, 2019.

[6] T. Kim \& C. T. Lin, "Laser-Induced Breakdown Spectroscopy," In M. A. Farrukh, Advanced Aspects of Spectroscopy, pp. 131-164, 2012

[7] Laporan Tahunan Balai Besar Pom Di Jakarta 2018, Jakarta: BPOM, 2018.

[8] A. G. Pasyah, "Analisis Distribusi Timbal Sebagai Emisi Gas Buang Kendaraan Bermotor dengan Teknik Laser-Induced Breakdown Spectroscopy (LIBS)," Prosiding Seminar Nasional Fisika (E-Journal) SNF2019, pp. 161-166, 2019.

[9] Peraturan Bersama Menteri Dalam Negeri Republik Indonesia Dan Kepala Badan Pengawas Obat Dan Makanan Republik Indonesia, Jakarta, 2013.

[10] A. Sarkar, et al., "Determination of sub-ppm levels of boron in ground water samples by laser induced breakdown spectroscopy," Springer, pp. 65-69, 2009. 
[11] R. Septiani, M. A. Marpaung \& M. M. Suliyanti, "Identifikasi Kandungan Unsur-Unsur Varietas Serbuk Kopi Dengan Teknik Laser Induced Shock Wave Plasma Spectroscopy," Spektra: Jurnal Fisika dan Aplikasinya, pp. 15-22, 2017.

[12] Standard Methods for Examination of Water and Wastewater 23rd Edition, Washington DC: American Public Health Association, 2017.

[13] M. M. Suliyanti, "Aplikasi Laser Dalam Analisa Unsur Dengan Teknik Pembangkitan Plasma Dan Metode Pelapisan. Jurnal Fisika - Himpunan Fisika Indonesia," pp. 37-44, 2010.

[14] H. Suyanto, M. Manurung \& D. N. Sinaga, "Studi Perbandingan Analisis Unsur Plumbum $(\mathrm{Pb})$ dari Hasil Elektrolisis Antara Metode Laser Induced Breakdown Spectroscopy (LIBS) dengan Metode Konvensional,” Jurnal Pendidikan Fisika Indonesia, pp. 178-185, 2014. 